\title{
Desafios enfrentados por pedagogas na utilização de uma nova plataforma: aulas remotas em tempos de pandemia da COVID-19
}

\author{
Challenges faced by pedagogies in using a new platform: remote classes in times of the COVID-19 \\ pandemic
}

Desafíos de los pedagógistas en el uso de una nueva plataforma: clases remotas en tiempos de la pandemia COVID-19

Anderson Fernandes de Miranda

ORCID: https://orcid.org/0000-0001-9251-572X Universidade do Estado de Mato Grosso, Brasil

E-mail: anderson@unemat.br

Geison Jader Mello

ORCID: https://orcid.org/0000-0002-0991-2327

\begin{abstract}
Resumo
Diversos foram os impactos, os estudos e as discussões a respeito dos desafios enfrentados exclusivamente por professoras que atuam nos anos iniciais do ensino fundamental em tempos de pandemia da COVID-19. Da relevância destes impactos surge a motivação para a presente pesquisa que teve como objetivo compreender e discutir as dificuldades didáticas pedagógicas encontradas pelas professoras dos anos iniciais do ensino fundamental de uma Escola Estadual Pública em Juína-MT, ao utilizar a plataforma Microsoft Teams® para ministrar aulas durante a pandemia do COVID-19, em 2020. A investigação pode ser caracterizada como um estudo de caso de abordagem qualitativa. Para a produção de dados foi utilizado questionário com perguntas abertas e observação, direcionada as professoras de $1^{\circ}$ ao $5^{\circ}$ ano de uma escola pública, em Juína-MT. A análise dos dados foi realizada segundo a análise de conteúdo de Laurence Bardin. Os resultados apontam que a plataforma Microsoft Teams® era desconhecida por todas as professoras envolvidas na pesquisa, surgindo então como um desafio no que tange ao desenvolvimento das aulas. Os principais desafios evidenciados pelas participantes foram: dificuldades com o manuseio da nova plataforma, rede de internet precária, escassa participação dos estudantes e falta de interesse, pouco envolvimento da família no processo escolar dos filhos, além da falta de recursos tecnológicos por parte dos alunos, mostrando grande desigualdade social de acesso. Soma-se também momento de insegurança no uso da referida plataforma devido ser algo novo para todos e muitas vezes o novo traz a insegurança manifestada nas palavras dos participantes. Portanto, durante o ano de 2020 no contexto da pandemia da COVID-19 os participantes precisaram conviver e superar desafios de natureza tecnológica, formativa e de acesso aos recursos tecnológicos essenciais ao bom andamento do ensino remoto.
\end{abstract}

Palavras-chave: Ensino remoto; Plataformas digitais; Exclusão social.

\section{Abstract}

There were several impacts, studies and discussions about the challenges faced exclusively by teachers who work in the early years of elementary school in times of the COVID-19 pandemic. From the relevance of these impacts comes the motivation for the present research, which aimed to understand and discuss the didactic-pedagogical difficulties encountered by teachers of the early years of elementary school in a state public school in Juína-MT, when using the Microsoft Teams ${ }^{\circledR}$ platform to teach classes during the COVID-19 pandemic in 2020. The investigation can be 
characterized as a case study with a qualitative approach. For the production of data, a questionnaire with open questions and observations was used, directed to teachers from the 1st to 5th grade of a public school in Juína-MT. Data analysis was performed according to Laurence Bardin's content analysis. The results show that the Microsoft Teams ${ }^{\circledR}$ platform was unknown to all the teachers involved in the research, thus emerging as a challenge with regard to the development of classes. The main challenges highlighted by the participants were: difficulties in handling the new platform, precarious internet network, scarce student participation and lack of interest, little family involvement in the children's school process, in addition to the students' lack of technological resources, showing great social inequality of access. There was also a moment of insecurity in the use of the referred platform because it was something new for everyone, and the "new" often brings out the insecurity expressed in the words of the participants. Therefore, during the year 2020, in the context of the COVID-19 pandemic, participants needed to spend more time together and overcome challenges of technological, training nature and problems with the access to technological resources essential for the smooth running of remote education.

Keywords: Remote learning; Digital platforms; Social exclusion.

\section{Resumen}

Este estudio trae discusiones sobre los desafíos que enfrentan exclusivamente los maestros que trabajan en los primeros años de la escuela primaria en tiempos de la pandemia de COVID-19. Así, esta investigación tuvo como objetivo comprender y discutir las dificultades didácticas pedagógicas encontradas por los docentes en los primeros años de la escuela primaria de un Colegio Público Estatal de Juína-MT, al utilizar la plataforma Microsoft Teams® para impartir clases durante el COVID-19, en 2020. La investigación se puede caracterizar como un estudio de caso con un enfoque cualitativo. Para la producción de datos se utilizó un cuestionario con preguntas abiertas y observación, dirigido a los maestros de $1^{\circ}$ a $5^{\circ}$ grado de una escuela pública de Juína-MT. El análisis de datos se realizó de acuerdo con el análisis de contenido de Laurence Bardin. Los resultados muestran que la plataforma Microsoft Teams ${ }^{\circledR}$ era desconocida para todos los docentes involucrados en la investigación, emergiendo, así como un desafío en lo que respecta al desarrollo de las clases. Los principales desafíos resaltados por los participantes fueron: dificultades en el manejo de la nueva plataforma, mala señal de internet (siempre caída), escasa participación de los estudiantes y desinterés por parte de ellos, poca implicación familiar en el proceso escolar de los niños, además de la falta de tecnología. recursos por parte de los estudiantes, mostrando una gran desigualdad social de acceso. También hay un momento de inseguridad en el uso de la referida plataforma porque es algo nuevo para todos y muchas veces lo nuevo trae la inseguridad expresada en las palabras de los participantes. Por ello, durante el año 2020, en el contexto de la pandemia COVID-19, los participantes necesitaron convivir y superar los desafíos de una tecnología, la formación y el acceso a los recursos tecnológicos imprescindibles para el buen funcionamiento de la educación a distancia.

Palabras clave: Aprendizaje a distancia; Plataformas digitales; Exclusión social.

\section{Introdução}

No início de 2020, o mundo entrou em distanciamento social com intuito de diminuir o contágio pelo vírus da COVID-19, também chamado de Coronavírus, que se alastrou de forma global. As aulas foram suspensas, e pela necessidade de sua continuidade elas só foram possíveis por meio de sistema remoto, com o uso de tecnologias digitais (Cordeiro, 2020; Moreira, Henriques, Barros, 2020).

As tecnologias têm reconfigurado a sociedade em geral ao longo do tempo. Elas estão cada vez mais presentes na vida das pessoas e em todos os ambientes. A educação, além de muitas outras formas de trabalho, acontece nesse momento por meio desses recursos tecnológicos. Na visão de Mota (2020), o ensino está sendo tragado, rapidamente, em direção ao centro do vórtex digital. Assim, aquilo que já estava em andamento, fruto da impressionante aceleração digital, com a vinda da pandemia, fez com que tudo se antecipasse e se precipitasse em espaços temporais mais diminutos (Mota, 2020).

Durante a pandemia do COVID-19 novos desafios surgiram no campo educacional, além dos que já existiam. As tecnologias digitais foram exigidas e demandadas de uma hora para outra e professores iniciaram o ensino remoto com pouca ou nenhuma experiência no assunto.

Os desafios para ministrar aulas online são grandes, os recursos precisam primeiramente ter parâmetros de qualidade, para assim oferecerem maior eficácia e a desigualdade de acesso por parte dos estudantes são formidáveis, pois nem todos possuem computadores conectados à internet. Todavia, essa forma de ensino foi a melhor opção para minimizar o atraso no retorno às aulas presenciais (Cordeiro, 2020; Duarte, Medeiros, 2020)). 
A motivação para o desenvolvimento desta pesquisa reportada no presente artigo se deu diante da necessidade de refletir sobre as dificuldades e desafios que professores vêm enfrentando no presente em um contexto pandêmico, onde tiveram que se afastar de pessoas, do trabalho, da escola, ou seja, da vida social. Sendo assim, surge a questão: Quais desafios os professores dos anos iniciais do ensino fundamental têm enfrentado ao utilizar a plataforma Microsoft Teams® para ministrar aulas remotas durante a pandemia?

Para tanto, o objetivo dessa pesquisa foi compreender e discutir as dificuldades didáticas pedagógicas encontradas pelas professoras dos anos iniciais do ensino fundamental de uma Escola Estadual Pública em Juína-MT, ao utilizar a plataforma Microsoft Teams® para ministrar aulas durante a pandemia do COVID-19, em 2020.

\section{Metodologia}

O presente trabalho configura-se como um estudo de caso de abordagem qualitativa. Para Gil (2008, p. 57-58) "o estudo de caso é caracterizado pelo estudo profundo e exaustivo de um ou de poucos objetos, de maneira a permitir o seu conhecimento amplo e detalhado, tarefa praticamente impossível mediante os outros tipos de delineamentos considerados". Sendo assim, nossa pesquisa se classifica quanto a esse procedimento devido ao estudo de um caso específico - os desafios enfrentados pelas pedagogas no uso de plataforma para ministrar aulas em tempo de pandemia do COVID-19.

Relativo à abordagem qualitativa, Sampieri e Lucio (2013) enfatizam que essa abordagem é indicada quando se busca compreender a perspectiva dos participantes sobre os fenômenos que os rodeiam.

A pesquisa qualitativa busca criar uma descrição rica sobre um determinado fenômeno, descobrindo relações que auxiliem o leitor a entender aspectos mais profundos, de modo que se produza uma melhor compreensão do objeto de estudo (Teodoro et al., 2018). Portanto, é considero o método qualitativo mais propício para o desenvolvimento da referida pesquisa.

Como instrumento de produção de dados foi utilizado um questionário com cinco perguntas abertas e observação in loco. O questionário pode ser definido como uma "técnica de investigação composta por um conjunto de questões que são submetidas a pessoas com o propósito de obter informações sobre conhecimentos, crenças, sentimentos, valores, interesses, expectativas, aspirações”, etc (Gil, 2008, p. 121).

O referido questionário foi direcionado as professoras pedagogas que atuam do $1^{\circ}$ ao $5^{\circ}$ ano em uma escola pública na cidade de Juína-MT. O questionário foi enviado via WhatsApp®. De todas as professoras da escola, cinco participaram da pesquisa e responderam ao questionário. As professoras foram denominadas, sujeitos dessa investigação, com a letra "P" seguida das letras do alfabeto (P1; P2; P3; P4 e P5), como descrito no termo de livre esclarecimento (CEP: 4.510.028).

A aplicação do questionário aconteceu no mês de janeiro do ano de 2021 e buscou compreender e discutir as dificuldades didáticas pedagógicas encontradas pelas professoras dos anos iniciais do ensino fundamental de uma Escola Estadual Pública em Juína-MT, ao utilizar a plataforma Microsoft Teams® para ministrar aulas durante a pandemia do Covid19, em 2020. O questionário segue no quadro abaixo:

Quadro 1 - Questionário aberto.

01- Quais desafios você encontrou ao utilizar a plataforma Microsoft Teams ${ }^{\circledR}$ ?

02- Quantos dos seus estudantes participam das aulas online e realizam as atividades propostas?

03- Foram realizadas formações para a utilização da Plataforma Microsof Teams®?

04- Ao surgirem dúvidas e dificuldades ao usar a plataforma Microsoft Teams® a quem recorriam?

05- Na sua avaliação, a utilização da plataforma Microsoft Teams ${ }^{\circledR}$ foi útil para dar continuidade às aulas em tempo de pandemia? Explique. 
Para a análise e interpretação dos dados foi adotado a análise de conteúdo de Laurence Bardin (2016). Um método empírico, compreendido como um conjunto de técnicas e instrumentos que visa à compreensão dos significados das falas ou mensagens recebidas, direcionada a discursos diversos.

\section{Das Aulas Presenciais para as Aulas Remotas: a Utilização da Plataforma Microsoft Teams®}

Quando as aulas foram suspensas em 2020 devido a pandemia do COVID-19, professores tiveram que começar a ministrar aulas através de telas de celulares e computadores, via WhatsApp ${ }^{\circledR}$, chamada de vídeo, por áudio, aulas gravadas; sempre procurando um meio mais adequado para oferecer o ensino. Não só a escola, mas outras instituições e empresas tiveram que migrar para o trabalho remoto com a chegada da pandemia (Microsoft, 2020).

De acordo com Vieira e Ricci (2020, p. 01) que a "situação iniciada a partir do contágio mundial em massa pelo COVID-19, ainda que se trate de uma questão de saúde pública, afetou o cenário mundial em seus mais diversos campos, trazendo consequências econômicas, políticas, sociais e, logo, também, ao campo educacional”.

Nesse contexto, a empresa Microsoft ${ }^{\circledR}$, ofereceu o uso de uma de suas plataformas, a plataforma Microsoft Teams®, para diversas organizações e escolas a fim de dar suporte às áreas da educação, da saúde e outras. Microsoft Teams® é uma central segura de trabalho em equipe, em que todos os usuários conectados podem fazer reuniões, ligações, compartilhar tela, e demais ações (Microsoft, 2020).

Para o uso da referida plataforma a Secretaria da Educação do Estado de Mato Grosso (SEDUC-MT), disponibilizou através dos Centros de Formação e Atualização dos Profissionais da Educação Básica de Mato Grosso (CEFAPROS), uma formação para retorno das atividades escolares não presenciais, com intuito de auxiliar os professores da rede estadual de ensino no manuseio desse recurso.

Segundo Santana e Sales (2020) no âmbito da educação práticas pedagógicas emergentes surgem para lidarmos com a pandemia. Essas práticas acabam por trazer maiores desafios, além daqueles que o segmento já vinha enfrentando. Na área da educação, com a necessidade de soluções imediatas para o desenvolvimento das atividades escolares em tempos de pandemia, novas estratégias, procedimentos e técnicas foram ocupando espaço nas rotinas das escolas. Esta paralisação imediata trouxe ao centro do debate educacional, o uso das tecnologias educacionais para realização de atividades escolares não presenciais (Vieira \& Ricci, 2020).

Nesse contexto, as salas de aula formaram um novo cenário, os livros digitais ganharam o lugar dos livros físicos, os alunos que falavam o tempo todo agora ficavam escondidos atrás de uma tela com o microfone desativado. A presença física foi trocada por fotos de perfis, a didática do professor teve que ser repensada obrigatoriamente da noite para o dia (Casado, 2020).

Os arquivos PDF (sigla do inglês Portable Document Format, que significa Formato de Documento Portátil), os vídeos e as fotos passaram a serem utilizados em vez do quadro e o giz. As discussões coletivas foram substituídas pelos áudios. Portanto, a pandemia causada pelo Coronavírus (Covid-19) mudou a imagem que foi construída acerca de escola e da educação historicamente e agora os recursos tecnológicos têm sido os meios disponíveis (e principais) para que o ensino seja oferecido e as aulas aconteçam (Casado, 2020).

Não há dúvidas que a pandemia do COVID-19 implicará em perdas para a educação e acarretará prejuízos para a aprendizagem e o desenvolvimento de milhares de estudantes de todo o mundo (Santana \& Sales, 2020). Desse modo, "diante do isolamento social, determinado com maior ou menor rigor nos mais diferentes países, noticiou-se, logo nos primeiros 30 dias de contágio mundial e massivo do vírus, o alcance do número de 300 milhões de crianças e adolescentes fora da escola" (Vieira \& Ricci, 2020, p. 01). 
O contexto educacional que já vinha enfrentando desafios perante as transformações sociais contemporâneas ocorridas, agora em razão do cenário pandêmico ganhou novas proporções e novos contornos mais preocupantes. A pandemia da COVID-19 provocou o fechamento de muitas escolas devido as medidas de proteção que foram implantadas pela Organização Mundial da Saúde (OMS). As medidas impostas, no entanto, foram mais físicas do que sociais. Em cenário global, as pessoas migraram suas interações para os ambientes virtuais (Santana \& Sales, 2020).

De acordo com Insfran et al. (2020) destacam que nestes tempos de pandemia:

Especificamente falando do campo da educação, temos vivido desde o início do isolamento dilemas e conflitos com relação ao modelo de ensino imposto, que trouxe para a realidade de milhões de pessoas, da noite para o dia, ferramentas tecnológicas com as quais grande parte da população tem pouca ou nenhuma familiaridade. Tanto professoras/es (que se tornaram youtubers em aulas ao vivo e/ou gravadas) como alunos/as e suas famílias têm feito queixosos relatos de dificuldades nesta modalidade de ensino remoto (Insfran et al., 2020, p. 12).

Na visão dos autores, mais uma vez um novo e desconhecido modelo é introduzido na educação sem diálogo com o chão de escola, sem levar em consideração as condições sociais, materiais, tecnológicas, logísticas, emocionais e físicas de professores, estudantes e famílias (Insfran et al., 2020).

Dessa forma, todos tiveram que se reinventar e se adaptar às aulas remotas para dar continuidade nas atividades escolares, usando para isso a internet, os computadores, celulares e outros aparelhos tecnológicos, além de aplicativos e plataformas desconhecidas (Nunes, 2020; Insfran et al., 2020).

\section{Formação de Professores e as Tecnologias Digitais}

Cordeiro (2020) destaca que diante das aulas remotas muitos educadores tiveram que adaptar suas aulas, utilizando os recursos digitais, ressaltando que nem todos os educadores brasileiros, tiveram formação adequada para lidarem com esses novos recursos digitais, reaprendendo-os novas maneiras de ensinar.

Nesse sentido, as reflexões em torno das práticas pedagógicas no âmbito escolar têm se tornado cada vez mais presente na busca de políticas públicas, as quais visam a melhoria na qualidade do ensino. Com isso, as escolas ao logo do tempo tem se modernizado para suprir as necessidades educacionais dos alunos, uma vez, que a tecnologia digital está presente no dia a dia, desde o nascimento. Martins e Maschio (2014), afirmam que à escola contemporânea, a introdução das Tecnologias de Informação e Comunicação (TIC) tem levado os pesquisadores da educação a investigar e debaterem sobre a transformação dos modos como a escola ensina, e as formas como os alunos aprendem no contexto dos avanços tecnológicos digitais.

Kenski (2009) e Imbernón (2010), ressaltam que um dos grandes desafios que os professores enfrentam está na necessidade de saber lidar pedagogicamente com os alunos, as tecnologias digitais, destacando que o desafio maior se encontra na própria formação docente.

Para Kenski (1997) e Levy (2010), as tecnologias redimensionam o espaço da sala de aula em, pelo menos, dois aspectos. O primeiro diz respeito aos procedimentos realizados pelo grupo de alunos e professores no próprio espaço físico da sala de aula. Neste ambiente a possibilidade de acesso a outros locais de aprendizagem-bibliotecas, museus, centros de pesquisas, outras escolas etc. com os quais os alunos e professores podem interagir e aprender-modificar toda a dinâmica das relações de ensino e aprendizagem. Em um segundo aspecto, é o próprio espaço físico da sala de aula que também se altera.

Conforme Kerckhove (1997, p. 245) argumenta que a solução "está em mudarmos as nossas percepções e não apenas as nossas teorias". Compreender este novo mundo no qual estamos entrando com uma nova lógica, uma nova cultura, uma nova sensibilidade, uma nova percepção. 
Kenski (2007) acrescenta que a formação dos professores para o uso das novas tecnologias deve: identificar quais as melhores maneiras de usar as tecnologias para abordar um determinado tema ou projeto específico ou refletir sobre eles, de maneira a aliar as especificidades do "suporte" pedagógico (do qual não se exclui nem a clássica aula expositiva nem, muito menos, o livro) ao objetivo maior da qualidade da aprendizagem de seus alunos (Kenski, 2007).

Gabriel (2013) e Kenski (2002), afirmam que há a necessidade de avançar nas ações de formação docente para além da simples instrumentalização no uso de recursos tecnológicos. A preocupação ocorre em nível didático, porque o desafio do professor é pensar em possibilidades de utilização; uma vez que estão acostumados com uma educação pouco interativa.

Dentro dessa realidade a formação do professor também deve dar instrumentos para que estes desenvolvam práticas inovadoras utilizando as tecnologias digitais, incluindo-as na prática pedagógica de sala de aula. Nessa perspectiva, Valente (1998) afirma que:

[...] deve-se proporcionar ao professor as bases para que possa superar barreiras de ordem administrativa e pedagógica, possibilitando a transição de um sistema fragmentado de ensino para uma abordagem integradora de conteúdo e voltada para a elaboração de projetos temáticos do interesse de cada aluno. Finalmente, deve criar condições para que o professor saiba re-contextualizar o aprendizado e a experiência vivida durante sua formação para sua realidade de sala de aula, compatibilizando as necessidades de seus alunos e os objetivos pedagógicos que se dispõe a atingir. (Valente, 1998, p.6-7).

Nesse contexto, a nova função da escola, na qual o/a professor/a deve ser o mediador da interação dos alunos com os meios de comunicação, bem como, orientando-os na maneira de navegarem nos conhecimentos presentes nas tecnologias de forma crítica e na busca das informações que os façam construírem uma aprendizagem significativa (Gadotti, 2000; Pascoin \& Carvalho, 2021).

A este respeito Melo e Silva (2020) e Pascoin e Carvalho (2020; 2021), enfatizam a importância da formação continuada dos professores, pois somente através da capacitação docente é que será possível propiciar uma educação de qualidade, ressaltando a importância do domínio docente dos recursos tecnológicos, os quais serão utilizados como apoio para melhorar os processos de ensino e aprendizagem.

Enfim, na perspectiva da construção de uma escola renovada, apta a responder às exigências de uma sociedade em permanente mudança, em que as tecnologias estão presentes no cotidiano de todos, percebe-se a necessidade de uma reflexão profunda sobre a formação continuada dos docentes, numa lógica global, pois a pandemia do COVID-19 fez com que a prática docente tivesse que ser modificada a realidade habitual dos educadores no mundo inteiro proporcionando a estes o desafio de suprir as necessidades dos educandos mantendo a qualidade do ensino (Casado, 2020; Nunes, 2020; Insfran et al., 2020).

\section{Resultados e Discussão}

Como mencionado na metodologia as participantes foram nomeadas com a letra "P" seguida das letras na ordem P1; P2; P3; P4 e P5, onde responderam cinco perguntas abertas. A primeira questão levantada pelas pesquisadoras foi "Quais desafios você encontrou ao utilizar a plataforma Microsoft Teams®? As seguintes respostas foram obtidas:

\footnotetext{
"Em fazer com que os pais enviassem as atividades para correção e com a internet, porque o app é muito pesado e puxa muita internet, sempre durante as aulas caia" (P1, 2020).

“Aprender utilizar a plataforma, orientar os pais através do whatsapp ${ }^{\circledR}$ como utilizar a plataforma, orientar os alunos a utilizar a barra flutuante para ligar e desligar o microfone, plataforma pesada. $O$ maior desafio acredito que é a falta de recursos, eu tenho muitos alunos que não tem condições de ter uma boa internet ou um computador" $(P 2,2020)$.
} 
"Não sei mexer com tecnologia, portanto, foi um desafio trabalhar com tecnologia para mim, eu conheço muito pouco os recursos tecnológicos, sei apenas utilizar o Whats (whatsapp ${ }^{\circledR}$ ) e ligar, mexer no Word® um pouco e lançar as coisas no sistema. O sinal sempre era ruim, os alunos reclamavam muito e quase não tinha contato com os pais" (P3, 2020).

"Utilizar a plataforma era difícil no começo, pois era desconhecida pra mim, e as formações não ajudaram muito, porque acho que aprendemos mesmo é na prática. Outro desafio foi fazer os alunos participarem, porque a maioria entrava, mas não fazia nada" (P4, 2020).

"O primeiro desafio foi baixar e fazer o login na plataforma, isso deu muito problema para mim e para outros professores e alunos, a gente nunca tinha ouvido falar dela, a internet também caia muitas vezes durante as aulas, os alunos pouco motivados e interessados (infrequentes) e fata de cobrança dos pais para com seus filhos” (P5, 2020).

Diante das respostas pode ser observado a dimensão do desafio que representou o uso da plataforma Microsoft Teams® nas aulas remotas, em decorrência da falta de uma boa conexão de internet como nas palavras de P1 “porque o app é muito pesado e puxa muita internet, sempre durante as aulas caia" e dificuldades dos pais de alunos em enviar as atividades de ensino, que P1 descreveu ser um desafio “Em fazer com que os pais enviassem as atividades para correção”. Nas palavras de P3 os desafios foi aprender a utilizar a plataforma no ensino remoto por não saber "mexer com tecnologia, portanto, foi um desafio trabalhar com tecnologia para mim, eu conheço muito pouco os recursos tecnológicos, sei apenas utilizar o Whats e ligar, mexer no word um pouco e lançar as coisas no sistema”, além da conexão com a internet ter sido também um desafio. As respostas de P2, P4 e P5 corroboram com as palavras de P2 e P3, mostrando que os desafios foram múltiplos, mostrando que diante das aulas remotas, devido a pandemia do COVID-19, muitos educadores tiveram que adaptar suas aulas, utilizando os recursos digitais, tendo que aprender a utilizá-los em tempo recorde e assumir múltiplas funções.

Segundo Vieira e Ricci (2020, p. 01) diante da pandemia, “foi demandada, por parte dos docentes, a capacidade de experimentar, inovar, sistematizar esse conhecimento [...], fazendo o melhor uso possível dessas ferramentas, cujo uso, para muitos, era até então desconhecido" (grifo nosso).

Analogamente, com o surgimento da pandemia da COVID-19 "as instituições educacionais se empenham na busca de novas modalidades de estudo, como o suporte das tecnologias digitais" (Cordeiro, 2020, p. 01).

Em tal contexto, cabe acrescentar que as palavras das professoras mostram que é indispensável a formação dos professores para o uso das tecnologias, de modo a permitir que eles conheçam as melhores maneiras de usá-las para abordar um determinado tema, de maneira a aliar as especificidades do "suporte" pedagógico ao objetivo maior da qualidade da aprendizagem de seus alunos (Kenski, 2007; Pascoin \& Carvalho, 2021).

Sobre a segunda pergunta, está baseou-se em "Quantos dos seus estudantes participam das aulas online e realizam as atividades propostas?" São apresentadas as respostas das participantes no quadro abaixo:

Quadro 2 - Respostas das participantes para a pergunta de número 2.

\begin{tabular}{|c|c|c|c|}
\hline Turma & $\mathrm{N}^{\mathbf{o}}$ de alunos & Participam das aulas & Entregam as atividades \\
\hline $1^{\mathbf{o}}$ ano & 30 & 9 & 7 \\
\hline $2^{\mathbf{o}}$ ano & 31 & 12 & 9 \\
\hline $3^{\mathbf{o}}$ ano & 25 & 11 & 8 \\
\hline $4^{\mathbf{o}}$ ano & 23 & 10 & 12 \\
\hline $5^{\mathbf{o}}$ ano & 27 & 16 & 9 \\
\hline
\end{tabular}

Fonte: Autores, baseada em dados fornecidos pelas participantes.

Percebe-se de acordo com o Quadro 2 a escassa participação dos estudantes nas aulas remotas por meio da plataforma Microsoft Teams®. Das cinco turmas, onde as pedagogas (sujeitos da pesquisa) são regentes, somente em uma delas a 
participação dos alunos chega a ser maior que 50\%. Sendo assim, as demais turmas não chegaram a 50\% de presença nas aulas via referida plataforma (atividades síncronas).

Uma das evidências para a pouca participação das aulas é que boa parte das famílias dos estudantes não possuem boas condições financeiras para ter uma internet com velocidade de conexão de qualidade ou aparelhos tecnológicos também de qualidade para participação nas aulas. Dessa forma, foi perceptível que há desigualdades sociais - os alunos que possuíam condições acessavam e os que não possuíam não participavam (observação in loco).

Na visão de Vieira e Vicci (2020, p. 01) "Seja em escala nacional ou mundial, apesar de todos os esforços empregados nestas ações, os sistemas de ensino têm esbarrado na fragilidade da educação. A pandemia evidenciou e lançou holofotes sobre as desigualdades, demonstrando o quanto ainda há por se fazer até que alcancemos”. O mundo com a pandemia vem apresentando fragilidades sociais (Santana \& Sales, 2020).

Sendo "assim, reflexões teóricas e dados sobre a crise sanitária e o desigual acesso à tecnologia e direitos básicos apontam para a necessidade de uma democracia participativa mais forte, com debate e elaboração coletiva de políticas públicas que garantam saúde e educação para todos" (Insfran et al., 2020, p. 01) (grifo nosso).

Nos tempos vividos as desigualdades estão afloradas, dado que, vemos acontecer com precariedade e exclusão a implantação do ensino remoto em diversas e milhares instituições de ensino espalhadas pelo mundo. Assim, a pandemia tem exposto as tensões sociais e deixa nítida a grande luta de classe que passamos (Insfran et al., 2020).

Por fim, a maior das preocupações "quanto a instauração do Ensino Remoto foi a utilização de ferramentas que promovessem a democratização do acesso ao saber" (Casado, 2020, p. 68).

Noutra perspectiva, tendo em vista entender se houve formações preparatórias para o uso plataforma Microsoft Teams®, a terceira pergunta consistiu em: "Foram realizadas formações para a utilização da Plataforma Microsof Teams®”? Onde algumas das participantes enfatizaram:

"Sim, houve rápidas formações. Essa formação foi oferecida pela CEFAPRO da minha cidade" (P2, 2020). "Sim, pelo CEFAPRO de Juina” (P3, 2020).

"Aconteceu sim as formações umas 2 semanas apenas antes de começar as aulas online e quem fez a formação foi a CEFAPRO” (P6, 2020).

Nesse intento, pode-se observar que houve formações específicas para a utilização da plataforma Microsoft Teams®, pelo CEFAPRO de Juína-MT, mas parece que foram insuficientes. Portanto, por mais que a formação aconteceu superficialmente os professores não ficaram à própria sorte, desamparados em relação ao manuseio da plataforma.

Mas também, pode ser destacado que pela formação ter acontecido por um tempo relativamente curto, aproximadamente "duas semanas antes de começar as aulas online" como enfatiza P6, os professores não deixaram de ter dúvidas, medos e inseguranças em relação ao seu uso.

Nesse contexto, a pandemia trouxe junto consigo um cenário de medo e instabilidade, ocasionando até mesmo quadros psicológicos de ansiedade e depressão (Cordeiro, 2020), não se tratando apenas de professores, mas de uma maneira geral.

Docentes foram submetidos a momentos de estresse, pois "nem todos os educadores brasileiros, tiveram formação adequada para lidarem com essas novas ferramentas digitais" (p. 10). Porém, apesar de ser um caminho árduo, é essencial para a atual situação (Cordeiro, 2020).

Vale ressaltar que "os professores são os protagonistas no terreno da grande operação histórica da escolarização, assumindo a tarefa de promover o valor educação (Nóvoa, 1999, p. 18). Porém nesses novos tempos ninguém teve escolha, a maneira de se apropriar da educação foi imposta a todos - professores e alunos. 
Essa apropriação "transpôs a educação para contextos remotos desconsiderando, por força da necessidade emergencial" (Santana \& Sales, 2020, P. 87).

Relativo à questão de número 4, buscou compreender como as professoras supriam suas dúvidas quando a plataforma apresentava problemas, ou tinham dificuldades com ela levantou-se a seguinte questão: “Ao surgirem dúvidas e dificuldades ao usar a plataforma Microsoft Teams® a quem recorriam?”

"Eu recorri ao pessoal do CEFAPRO da minha cidade, que eram os responsáveis pelo suporte aos professores. Ou seja, responsáveis pela formação e pela produção de muitos vídeos explicativos publicados na página do Youtube ${ }^{\circledR}$ ” (P1, 2020).

“Eu ia atrás de todas as pessoas, dos profissionais da escola, família, colegas e amigos, gestão escolar” (P4, 2020).

"Recorria sempre aos funcionários da escola e algumas vezes ligava para o suporte da plataforma Microsoft ${ }^{\circledR}$ e até assistia vídeos fornecidos pela própria Microsoft ${ }^{\circledR}$, e também vídeos encaminhados por outras pessoas “ (P5, 2020).

"Eu buscava ajuda na secretaria da escola e com meus colegas de profissão, pois com eles também davam aulas talvez alguns dominavam a ferramenta mais que os outros “ (P6, 2020).

Segundo as informações fornecidas quando surgiam dúvidas e dificuldades em lidar/utilizar a plataforma Microsoft Teams®, cada professora buscava ajuda de uma forma diferente e se ajudavam entre si.

Sendo assim, recorriam ao CEFAPRO que foi responsável pela formação de preparo ao manuseio da plataforma, mas também a equipe gestora (diretora e coordenadora), a secretaria, demais professores da escola, outros colegas professores, suporte da plataforma Microsoft Teams® ${ }^{\circledR}$ ou ainda por meio de vídeos da internet e consultas aos familiares e amigos.

Nesse sentido, para Valente (1998) precisamos nos atentar ao fato de que para a implementação da tecnologia na escola são necessários quatro ingredientes, sendo um deles o professor capacitado para usar essas tecnologias (grifo nosso). O que também de fato, não aconteceu com a vinda da pandemia, afinal, pode-se contatar diante das respostas dos sujeitos da pesquisa que eram imensas as dúvidas e dificuldades no uso da plataforma - um recurso tecnológico.

Santos Junior e Monteiro (2020) afirmam que essas dificuldades se devem a formação de docentes aptos a utilizar as tecnologias em função do aprendizado o qual tem sido o principal desafio dos cursos de licenciaturas, pois os professores ainda recebem uma formação voltada para os modelos tradicionais de ensino, trazendo deficiência em suas práticas, que não estão em harmonia com o cenário atual. Tornando-se necessário ser pensado e adaptado à contemporaneidade.

Em relação a quinta e última pergunta de nosso questionário, está foi baseada na avaliação dos recursos tecnológicos na percepção das pedagogas, consistindo em: "Na sua avaliação, a utilização da plataforma Microsoft Temas foi útil para dar continuidade às aulas em tempo de pandemia? Explique”. Seguem as respostas:

"Quem estava na plataforma conseguiu desenvolver bem e aprendeu bastante não igual presencial, mas teve um bom rendimento, quem estava na apostila não teve a aprendizagem satisfatória” (P1, 2020).

"Sim foram úteis, para os alunos que tinham internet para acessar a plataforma. Porém para os alunos que não tinham internet ficou à desejar” (P2, 2020).

"Sim, foi muito útil, útil demais, porque foi a única forma que a gente nesse momento podia dar sequência aso conteúdos, pena que na minha turma a maioria dos alunos não tinham condições de comprar um celular ou adquirir um comutador, e os que tinham a internet era ruim, de baixa qualidade, e o app pesava demais. Agora, se todos tivessem seria excelente" (P3, 2020).

"Os alunos interessados tiveram orientações para avançarem nós estudos os demais não participaram das aulas, porém não adquiriram o conhecimento necessário. Mas de forma presencial podemos fazer muito mais, os alunos aprendem mais" (P4, 2020). 
"Foram úteis devido à situação, porém nada substitui as aulas presenciais, onde o professor tira as dúvidas mesmo daquele aluno que não pergunta, mas que ao olhar o caderno o professor percebe que o mesmo não compreendeu o conteúdo. Além de que, os alunos que não tiveram acesso à internet não tiveram o mesmo incentivo para realizarem as atividades sozinhos em casa” (P5, 2020).

"Os recursos tecnológicos foram muito úteis durante a pandemia para a apropriação das aulas, sem eles não seria possível dar continuidade ao ano letivo, porém devemos lembrar que nada se compara em estar presente com os alunos, eles aprendem melhor" (P6, 2020).

Percebe-se, que as participantes destacam a importância da utilização da plataforma Microsoft Teams® e dos recursos tecnológicos durante as aulas remotas, sendo muito útil, pois somente através dos recursos digitais como essa plataforma foi possível prosseguir com as aulas já em andamento como nas palavras de P3 "Sim, foi muito útil, útil demais, porque foi a única forma que a gente nesse momento podia dar sequência aso conteúdos, pena que na minha turma a maioria dos alunos não tinham condições de comprar um celular ou adquirir um comutador, e os que tinham a internet era ruim, de baixa qualidade, e o app pesava demais. Agora, se todos tivessem seria excelente". Nesse momento de pandemia com o isolamento social, onde os alunos foram impedidos de irem à escola, a educação remota torna-se um fator essencial e fundamental para esse novo contexto (Cordeiro, 2020).

Todavia, as professoras enfatizaram que as aulas remotas não conseguem suprir as necessidades e dificuldades dos alunos tanto quanto as aulas presenciais, e julgam a última como sendo a melhor forma de ensino. Dizendo de outra maneira, as aulas remotas jamais irão substituir as aulas presenciais, pois no contato "físico" é possível um melhor acompanhamento de todas as etapas do trabalho pedagógico. Ainda ressaltam que nem todos os estudantes tiveram acesso as aulas de forma online por causa da falta de recursos das famílias dos alunos, e por isso, sem alternativa, a maioria deles faziam atividades apenas pela apostila impressa.

Como argumenta Nóvoa (1999), os sistemas de educação tiveram dificuldades para lidar com essa crise de desigualdade. Porém, é preciso o entendimento de ser essencial agir em defesa de uma educação que seja, sobretudo, pautada na luta contra as desigualdades sociais.

Duarte e Medeiros (2020), destacam sobre aspectos limitadores/restritivos no processo de mediação pedagógica em tempos de pandemia, em que os docentes (sujeitos da pesquisa) apontaram como grandes empecilhos: as limitações de acesso à internet de qualidade, alguns aspectos metodológicos para os quais nem os professores nem os estudantes estavam habituados, falta de equipamentos (computadores, tablets, celulares, etc), o tempo para planejar as aulas e outros.

Umas das grandes dificuldades enfrentadas nesse período em que o mundo enfrentava a pandemia da COVID-19 foi a falta de interação entre professor e aluno e nesse momento o aluno teve que assumir o papel de sujeito no processo de ensino aprendizagem (Vygotsky, 2007; Pascoin \&Carvalho, 2020).

Nessa realidade, Castaman e Rodrigues (2020) destacam que um aspecto importante a ser discutido é a motivação e autonomia que essa modalidade de ensino exige do educando, talvez a falta de proatividade dos discentes não seja apenas um reflexo das aulas remotas, tendo em vista o fato de que mesmo em aulas presenciais o processo ainda é centrado no docente, nos métodos/metodologias e no conteúdo o que limita a autonomia discente.

Também é oportuno acrescentar a essas discussões, que por mais que os recursos tecnológicos foram essenciais para a continuidade de oferta do ensino, acreditando "que nenhum recurso é capaz de substituir a figura e a essencialidade do professor no processo de construção do conhecimento" (Casado, 2020, p. 00).

O professor sempre exerceu um papel essencial na educação e com esse novo mundo digital continuará exercendo, não apenas como quem transfere informações, mas como um catalisador de reflexões e conexões para os estudantes nesse ambiente mais complexo (Imbernón, 2010; Gabriel, 2013; Pascoin \& Carvalho, 2021). 


\section{Considerações Finais}

As professoras que participaram da pesquisa utilizaram a plataforma Microsoft Teams® que era desconhecida por elas, para ministrar as aulas durante a pandemia, que se consolidou como um dos muitos desafios enfrentados por essas profissionais. Entre outros desafios compreendidos estão a precariedade do sinal de internet, escassa participação dos alunos e falta de interesse em realizar as atividades, ainda o pouco envolvimento dos pais ou responsáveis no processo educativo dos estudantes e a falta de recursos digitais de qualidade por parte dos familiares pertencentes a comunidade escolar, com isso as desigualdades sociais foram acentuadas em demasia. Soma-se também momento de insegurança no uso da referida plataforma devido ser algo novo para todos e muitas vezes o novo traz a insegurança manifestada nas palavras dos participantes.

Considera-se através desta pesquisa que o ano de 2020 foi um ano atípico a todos os setores profissionais, em especial no âmbito educacional. Enfim, foram e são muitos os desafios a serem enfrentados, todavia, foi e está sendo possível promover a educação, por mais que ela não tenha alcançado a todos do mesmo modo.

Diante disso, acredita-se que globalmente é experimentando um novo paradigma, e ainda se tratando de "educação" também será necessário promover mudanças e preparar professores por meio de formações em relação ao uso da tecnologia, dado que, ela se tornou fundamental no ensino. É necessário também, que o caminho percorrido até aqui, além das aprendizagens desenvolvidas virtualmente por docentes a fim de enfrentar a pandemia sirva como reflexão para melhoria da prática pedagógica e da configuração e organização da escola observando a realizada de cada comunidade que a escola está inserida.

\section{Agradecimentos}

Os autores agradecem a CAPES, o PPGECM, a UNEMAT e todas as participantes da pesquisa pela contribuição para que a pesquisa se tornasse realidade.

\section{Referências}

Bardin, L. (2016). Análise de Conteúdo. Trad. Luís Antero Reto e Augusto Pinheiro. Edições 70.

Casado, S. F. P. Paradigmas de ensino em tempos de pandemia: anos iniciais do E.F. em debate. Revista aproximação. 2(5).

Castaman, A. S., Rodrigues, R. A. (2020). Educação à Distância na crise Covid -19: um relato de experiência. Research, Society and Development, 9(6).

Cordeiro, K. M. A. (2020). O impacto da pandemia na educação: a utilização da tecnologia como ferramenta de ensino. Faculdade IDAAM. http://repositorio.idaam.edu.br/jspui/handle/prefix/1157.

Duarte, K. A. \& Medeiros, L.S. (2020). Desafios dos docentes: As dificuldades da mediação pedagógica no ensino remoto emergencial. CONEDU:VII Congresso Nacional De Educação. https://editorarealize.com.br/editora/anais/conedu/2020/TRABALHO_EV140_MD1_SA19_ID6682_01102 020142727.pdf

Gabriel, M. (2013). Educar: $a$ ®evolução digital na educação. Saraiva.

Gadotti, M. (2020). Perspectivas atuais da educação. Perspec. 14(2).

Gil, A. C. (2008). Métodos e técnicas de pesquisa social. (6a ed.), Ediitora Atlas SA.

Imbernón, F. (2010). Formação continuada de professores. Artmed Editora.

Insfran, F. F. N., Prado, P. A. Do., Faria, S. E. F., Ladeira, T. A., Sentinelli, T. A., Junior, W. B. A pandemia da covid-19 como vitrine da precarização do trabalho docente e da educação: desafios para o ensino em uma democracia fragilizada. Revista Interinstitucional Artes de Educar. 6, 166-187 $10.12957 /$ riae.2020.52309.

Kenski, V. M. (2009). Educação e tecnologias: o novo ritmo da informação. (5a ed.), Papirus, 141p.

Kenski, V. M. (1997). Novas tecnologias. O redimensionamento do espaço e do tempo e os impactos no trabalho docente. Revista Brasileira de Educação, 8, 58-71. http://www.conhecer.org.br/download/INFORMATICA\%20EDUCATIVA/leitura\%20anexa\%203.pdf

Kenski, V. M. (2007). Educação e tecnologias: o novo ritmo da informação. Papirus. 
Research, Society and Development, v. 10, n. 14, e466101421753, 2021

(CC BY 4.0) | ISSN 2525-3409 | DOI: http://dx.doi.org/10.33448/rsd-v10i14.21753

Kenski, V. M. (2002). Processos de interação e comunicação no ensino mediados pelas tecnologias. In: Rosa, D. E. G., Souza, V. C. de (Org.). Didática e práticas de ensino: interfaces com diferentes saberes e lugares formativos. DP\&A, 254-264.

Kerckhove, D. (1997). A pele da cultura: uma investigação sobre a nova realidade eletronica. Lisboa:Relógio d’Água.

Levy, P. Cibercultura. Editora 34, 2010.

Martins, O. B. \& Maschio, E. C.F.: As Tecnologias Digitais na Escola e a Formação Docente: Representações, Apropriações e Práticas. Rev. Actual. Investig. Educ. 14(3). https://www.scielo.sa.cr/scielo.php?pid=S140947032014000300020\&script=sci_arttext\&tlng=pt.

Melo, D.K. F. \& Silva, A. S. (2020). Formação de professores: uma proposta de pesquisa a partir da reflexão sobre o uso das tecnologias educacionais nas práticas pedagógicas. Revista Educação \& Ensino, 4(2).

Microsoft. (2020). Microsoft oferece Microsoft Teams gratuitamente para manter organizações e escolas conectadas durante o COVID-19. Microsoft News Center Brasil. https://news.microsoft.com/pt-br/microsoft-oferece-microsoft-teams-gratuitamente-para-manter-organizacoes-e-escolas-conectadas-durante-ocovid-19/.

Moreira, J. A., Henriques, S., Barros, D. (2020). Transitando de um ensino remoto emergencial para uma educação digital em rede, em tempos de pandemia. Dialogia, 351-364.

Mota, R. (2020). Vórtex digital: a pandemia e o futuro da educação. https://pt.linkedin.com/pulse/vort\%C3\%A9x-digital-pandemia-e-o-futuro-daeduca\%C3\%A7\%C3\%A3o-ronaldo-mota.

Nóvoa, A. (1999). O passado e o presente dos professores. In: Nóvoa, A. et al. (Orgs.). Profissão professor. Porto Editora, 13-33.

Nunes, C. (2020). Conferência Magna sobre as Lições do Coronavírus e os impactos da pandemia na Educação e na Escola. CONAEDU. http://conaedumembros.paginas.digital/hub/content/32859.

Pascoin, A. F., \& Carvalho, J. W. P. (2021). Continuing education of teachers with digital technologies for teaching Chemistry. Saberes y prácticas. Revista de Filosofía y Educación, 6, 1-18.

Pascoin, A. F., \& Carvalho, J. W. P. (2020). Objeto digital de aprendizagem como proposta pedagógica para o ensino de química. Revista Eletrônica Científica Ensino Interdisciplinar, 6(17).

Sampieri, R. C., \& Lucio, C. M. (2013). Metodologia de Pesquisa. Penso Editora Ltda.

Santana, C. L. S. E, \& Sales, K. M. B. (2020). Aula em casa: educação, tecnologias digitais e pandemia covid-19. Interfaces Científicas - Educação, 10(1), 7592. https://doi.org/10.17564/2316-3828.2020v10n1p75-92.

Santos Junior, \& Monteiro, J. C. S. (2020). "Educação e Covid-19: As tecnologias digitais mediando a aprendizagem em tempos de Pandemia. Revista Encantar. 2, 01-15.

Teodoro, I. P. P., et al. (2018). Descrição interpretativa: uma abordagem metodológica viável para a pesquisa em enfermagem. Esc Anna Nery,22(3):e20170287.

Valente, J. A. (1998). Computadores e Conhecimento: representando a educação. (2a ed.), UNICAMP (NIED).

Vieira, L., Ricci, M. C. C. (2020). A educação em tempos de pandemia: soluções emergenciais pelo mundo. OEMESC - Observatório do ensino médio em Santa Catarina. Editorial de abril. https://www.udesc.br/arquivos/udesc/id_cpmenu/7432/EDITORIAL_DE_ABRIL__Let_cia_Vieira_e_Maike_ Ricci_final_15882101662453_7432.pdf.

Vygotsky, L. S. (2007). A formação social da mente. (7a ed.), Martins Fontes. 